\title{
Fast Triacylglycerol Screening and Semi-Quantitative Analysis of Fatty Acids in Commercial Oils by DIMS with 18-Crown-6 Ether/Trifluoracetic Acid Dopants
}

\author{
Angelica P. P. Tonin, ${ }^{\oplus a}$ Marcos A. S. Ribeiro, ${ }^{b}$ Camila B. Poliseli, ${ }^{b}$ Roberta da Silveira, ${ }^{c}$ \\ Jesuí V. Visentainer, ${ }^{a}$ Valquíria M. Silva, ${ }^{d}$ Leomara F. Ribeiro, ${ }^{d}$ Rodrigo C. T. de Souza, ${ }^{d}$ \\ Cláudio C. de Oliveira ${ }^{\circledR a}$ and Eduardo C. Meurer ${ }^{\circledR} * d$ \\ ${ }^{a}$ Departamento de Química, Universidade Estadual de Maringá (UEM), \\ Av. Colombo, 5790, 87020-900 Maringá-PR, Brazil \\ ${ }^{b}$ Departamento de Biotecnologia, Genética e Biologia Celular, \\ Universidade Estadual de Maringá (UEM), \\ Av. Colombo, 5790, 87020-900 Maringá-PR, Brazil \\ cPrograma de Pós-Graduação em Ciência de Alimentos, \\ Universidade Estadual de Maringá (UEM), 87020-900 Maringá-PR, Brazil \\ ${ }^{d}$ Laboratório Fenn de Espectrometria de Massas, Universidade Federal do Paraná (UFPR), \\ Campus Avançado Jandaia do Sul, 86900-000 Jandaia do Sul-PR, Brazil
}

\begin{abstract}
Vegetable oil analyses, especially due to the complexity of the oil components, are commonly laborious, requiring several analytical techniques. In this work, electrospray ionization mass spectrometry with direct injection (DIMS), along with 18-crown-6 ether (crown ether) chelating agent and trifluoroacetic acid (TFA), was used to characterize and semi-quantitatively evaluate commercial vegetable oils. As a result, an unprecedented DIMS method of triacylglycerols (TAGs) analysis for semi-quantitative profiling of fatty acids in commercial oils (e.g., soybean, sunflower, corn, oil, canola), without sample derivatization, was developed. The results of the ion abundances related to the analyzed TAGs, with quantitative percentage analyzed by gas chromatography with flame ionization detector (GC-FID), allowed generating correction factors for each oil. DIMS analysis with crown ether/TFA resulted in the elimination of isobaric interferences from sodium and potassium adducts, facilitating the ion assignments, due to the one-ion-per-molecule observation in the mass spectrum. Chemometric analyses by principal component analysis (PCA) and heatmap, to evaluate the ionic profile of the oils, grouped them accordingly to their TAG content. Olive oil was identified as the most different from the other oils. Overall, a semi-quantitative approach to investigate the vegetable oils, reaching low percentage variation for DIMS, with 2 min analyses and 30 min sample preparation, was proposed.
\end{abstract}

Keywords: mass spectrometry, vegetable oil, PCA analysis, ESI-MS

\section{Introduction}

Lipids are a large and diverse group of chemical compounds related by their solubility in nonpolar organic solvents. ${ }^{1}$ Lipids perform two critical functions: as the major structural components of biological membranes and a form of energy storage. Among the most commonly identified lipids, high molecular mass esters, such as fats, oils, and natural waxes, must be highlighted. ${ }^{2}$

*e-mail: eduardo.meurer@gmail.com
Vegetable oils are complex chemical mixtures composed primarily of lipid structures, such as triacylglycerols (TAGs), and small amounts of free fatty acids (FAs) and mono- and diacylglycerides from degradation processes. Crude vegetable oils also contain a variety of minor components, such as sterols, tocopherols, and phospholipids, but their distributions are characteristic of different types of oils. ${ }^{3,4}$ Lipid has a fundamental nutritional role, but its consumption is directly related to cardiovascular diseases, obesity, and insulin resistance. ${ }^{5}$

The FA composition of vegetable oils is traditionally used for oil classification and as an indicator of purity. ${ }^{6,7}$ 
Typically, the FAs that constitute TAG molecules of vegetable oils are analyzed by gas chromatography (GC), a process that necessitates the derivatization of the FAs. Many derivatization methods are described in the literature, but the majority involve the conversion of the FAs into corresponding esters, usually methyl esters. Regardless of the procedure used, quantitative methylation includes multiple steps and is a time-consuming process. Consequently, the analysis of oils, as well as their lipids, is highly challenging, as the components present a high degree of complexity and heterogeneity. Primarily, plant samples have a higher number of lipid molecules in comparison to animal and prokaryotic organisms.

Currently, there is no single analytical tool capable of identifying and quantifying all the lipid species simultaneously without combining various technologies. ${ }^{8}$ Most of the current methods of vegetable oils analysis are concentrated on the polar or nonpolar components of oils, using chromatographic techniques, such as GC; requiring extraction and derivation procedures. Altogether, these steps are considerably laborious and difficult to automate. ${ }^{9}$ Conversely, the search for faster, more efficient techniques with minimal preparation of the sample for the lipid analysis, has increasingly motivated the use of mass spectrometry (MS).

Electrospray ionization (ESI)-MS has been widely applied in the analyses of lipid from vegetable oils and seeds, as exemplified in the literature. ${ }^{9-12}$ Although these referred investigations, which evaluated the lipid profile and verified possible adulterations in olive oil, proved highly efficient, the TAG species occur as adducts of sodium $[\mathrm{M}+\mathrm{Na}]^{+},{ }^{10}$ and ammonium $\left[\mathrm{M}+\mathrm{NH}_{4}\right]^{+} .{ }^{11}$ These species overlap with oxidized TAG molecules, detected as $[\mathrm{TAG}(\mathrm{O})+\mathrm{Na}]^{+}$ions in the mass spectrum with unit resolution, since isobaric interference may occur with the non-oxidized TAG molecules. For example, the ion [TAG $(\mathrm{O}) \mathrm{C} 54: 6+\mathrm{Na}]^{+}$would exhibit the same nominal $\mathrm{m} / \mathrm{z} 917$ as that of $[\mathrm{C} 54: 6+\mathrm{K}]^{+}$, since oxygen plus sodium nominal mass is the same as potassium nominal mass of 39. This isobaric interference can be solved by the use of high-resolution MS, chromatographic separation, or tandem MS. ${ }^{13}$ In addition, ions [C52:3 $\left.+\mathrm{Na}\right]^{+}$and $[\mathrm{C} 54: 6+\mathrm{H}]^{+}$of $\mathrm{m} / \mathrm{z} 879$ may also overlap. ${ }^{14}$ Such "ion splitting" reduces sensitivity and greatly increases spectra complexity, making ion assignments a challenging task. In positive mode ESI(+), a molecule would therefore be sometimes detected either as $[\mathrm{M}+\mathrm{H}]^{+}$or $\left[\mathrm{M}+\mathrm{NH}_{4}\right]^{+}$with an $\mathrm{m} / z$ shift of $+16,[\mathrm{M}+\mathrm{Na}]^{+}$ with an $\mathrm{m} / z$ shift of $+22,[\mathrm{M}+\mathrm{K}]^{+}$with an $\mathrm{m} / z$ shift of +38 , and/or $[\mathrm{M}-\mathrm{H}+2 \mathrm{Na}]^{+}$with an $\mathrm{m} / \mathrm{z}$ shift of $+44 .^{14}$

Herein, we propose an unprecedented method of TAG analysis in commercial oils, which could also be applied to animal fats and add important information to the techniques already used for this purpose. ${ }^{15-18}$ The possible elimination of isobaric interferences from sodium and potassium adducts is achieved by the addition of the 18-crown- 6 ether complexing agent, using ESI-MS direct injection (DI) in positive mode DI-ESI(+)-MS (simplified as DIMS), and involves minimal sample preparation and reduced analysis time. Also, through the TAG profile, the percentage of FAs can be estimated, without the direct involvement of chromatographic techniques. Finally, two chemometric approaches were performed, involving principal component analysis (PCA) and heatmap analysis of the results obtained by DIMS.

\section{Experimental}

\section{Dopant testing and DIMS system conditions}

Formic acid and trifluoroacetic acid (TFA; Merck, Darmstadt, Germany) were tested at three levels (0.1, 0.3 , and $0.5 \%$ ) to optimize the ionization. Ultimately, $0.1 \% \mathrm{v} / \mathrm{v}$ TFA was selected as the best ionization inducer for the vegetable oil samples. Tests with 18-crown-6 ether (18-crown-6; Sigma-Aldrich, São Paulo, Brazil) as a sodium and potassium ion sequestering agent, were performed to favor protonated ions, and the optimum concentration was $0.68 \mathrm{mg} \mathrm{mL}^{-1}$.

\section{ESI(+)-MS analysis solutions}

Stock solutions of each sample were prepared by solubilizing $10.0 \mu \mathrm{L}$ of each oil sample (obtained from a local market) in $25.0 \mathrm{~mL} \mathrm{MeOH} \mathrm{(Sigma-Aldrich)} \mathrm{in}$ volumetric flasks. The dilution was conducted by vortexing $1.9 \mathrm{~mL}$ of $\mathrm{MeOH}$ acidified with $0.1 \%$ (v/v) TFA, $50.0 \mu \mathrm{L}$ of the stock solution of 18-crown-6 $\left(0.68 \mathrm{mg} \mathrm{mL}^{-1}\right)$ corresponding to a final concentration of $0.034 \mathrm{mg} \mathrm{mL}^{-1}$, and $50.0 \mu \mathrm{L}$ of the stock solution of oil, in an Eppendorf tube. Five $\mu \mathrm{L}$ of the final solution were immediately manually injected into a DIMS, for analyses of the TAGs. This procedure was conducted in triplicate for 15 brands of vegetable oils, with three brands of each type: olive, soybean, sunflower, corn, and canola oils. The conveyor solution (CS) was composed of $\mathrm{MeOH} / 0.1 \%$ TFA and $0.034 \mathrm{mg} \mathrm{mL}^{-1} 18$-crown-6.

\section{GC-flame ionization detector (FID) analyses}

TAGs in the samples were reacted by transesterification with $\mathrm{MeOH}$, using the method of Hartman and Lago, ${ }^{19}$ modified by Maia and Rodriguez-Amaya. ${ }^{20}$ Briefly, 
$100.0 \mathrm{mg}$ oil were weighed into a test tube and $4.0 \mathrm{~mL}$ of $0.50 \mathrm{~mol} \mathrm{~L}^{-1} \mathrm{NaOH} / \mathrm{MeOH}$ were added. The flask containing the mixture was heated in a boiling water bath for $5 \mathrm{~min}$, with subsequent cooling in water. About $5.0 \mathrm{~mL}$ of the esterifying reagent $\left(\mathrm{NH}_{4} \mathrm{Cl} / \mathrm{H}_{2} \mathrm{SO}_{4} / \mathrm{MeOH}\right)$ were added to the tube; the system was again heated in a water bath for $5 \mathrm{~min}$ and cooled in water. Next, $4.0 \mathrm{~mL}$ of saturated $\mathrm{NaCl}$ solution and $5.0 \mathrm{~mL}$ hexane were added to the tubes and shaken vigorously for $30 \mathrm{~s}$. Finally, the internal standard methyl ester (PI, 23:0 Me; Sigma, Darmstadt, Germany) was added. After phase separation, the upper phase was collected for injection into the GC-FID.

\section{Chemometric analyses (PCA and heatmap)}

The main component analysis method was used to analyze the raw data obtained from $[\mathrm{M}+\mathrm{H}]^{+}$species, based on $\mathrm{m} / \mathrm{z}$ and relative intensities (\%). The average of the spectra, in triplicate, was treated chemometrically, using the software Solo Matlab (R2006b). ${ }^{21,22}$ For the calculation of the PCA, the abundance data of the ions were normalized, by conversion into ion percentage. Accordingly, Table 1 was constructed, where, after the calculation, the standard deviation was added, obtained by use of the percentages of ions. For this calculation, only the ions with abundance above $3 \%$ in the $\mathrm{m} / \mathrm{z}$ region of $830-930$, where TAGs are located, were used. To verify the differences and similarities between the oils, it was constructed the heatmap that correlates the masses identified in the oils and their relative intensities, and also provides the PCA, with the difference of grouping of components. ${ }^{23}$

\section{DIMS conditions}

The analyses were conducted using a Premier XE triple-quadrupole mass spectrometer (Waters, Milford, MA, USA) with unit resolution under the optimized conditions: capillary voltage $3.5 \mathrm{kV}$, cone voltage $50 \mathrm{~V}$, extractor voltage $5 \mathrm{~V}$, desolvation temperature of $400{ }^{\circ} \mathrm{C}$, and gas flow of cone $300 \mathrm{~L} \mathrm{~h}^{-1}$. Nitrogen was used as nebulizer and desolvation gas. The analyses were performed with the MS operating in full scan mode.

\section{Semi-quantitative profile of FAs using DIMS}

To enable semi-quantitative estimation, all TAGs had the ionization capacity corrected with the results from GC-FID, see below. In this way, the obtained results could be compared to the literature data, showing the composition of the oils by the individual percentage of each TAG (Table 1$)$. These values ( $\%$ of intensity) for each identified
TAG obtained from the spectra were converted to the individual intensities of each identified FA for each TAG ion, and a calculated correction factor (Table 2) was applied using composition percentage originating from the GC-FID analyses. This correction factor method was applied to each oil evaluated, using one sample of each group, given their similarity. This approach allowed the use of DIMS for semi-quantitative and fast analyses, as expressed in Table 3, without the requirement of derivatization, and use of standards and analytical curves. This type of composition evaluation aimed to verify if the rapid analysis by MS approaches the consensus technique (GC-FID) as complementary information for the composition of oils.

\section{GC-FID conditions}

A TRACE Gas Chromatography Ultra (Thermo Scientific, Milan, Italy) equipped with an FID, split/splitless injector, and fused silica capillary column CP-7420 (Agilent Select FAME, Santa Clara, USA; 100 m length, $0.25 \mathrm{~mm}$ i.d. and $0.25 \mu \mathrm{m}$ cyanopropyl thin film as stationary phase) was used. The operation parameters were as follows: column temperature $165^{\circ} \mathrm{C}$ for $18 \mathrm{~min}$, heated to $235{ }^{\circ} \mathrm{C}\left(4^{\circ} \mathrm{C} \mathrm{min}^{-1}\right)$ and held for $20 \mathrm{~min}$; injector and detector temperatures were set at 230 and $250{ }^{\circ} \mathrm{C}$, respectively. Gas flows were $1.2 \mathrm{~mL} \mathrm{~min}^{-1}$ for carrier gas $\left(\mathrm{H}_{2}\right), 30 \mathrm{~mL} \mathrm{~min}^{-1}$ for makeup gas $\left(\mathrm{N}_{2}\right)$, and 30 and $300 \mathrm{~mL} \mathrm{~min}^{-1}$ of gas $\left(\mathrm{H}_{2}\right)$ and synthetic air, respectively, in the FID. Samples were injected in split mode (ratio of 40:1). The injection volume was $1.0 \mu \mathrm{L}$. Identification and quantification of the FAs were accomplished by comparing the retention time with the internal and external standards.

\section{Results and Discussion}

\section{Profile of TAGs}

To compare the vegetable oils of this study, a representative mass spectrum of each type of oil (soybean, sunflower, corn, canola, and olive; Figure 1) was used, since the TAG profiles observed among the various brands were very similar. The exception was olive oil, in which it was possible to note that among the three evaluated brands, one of them presented a TAG profile remarkably similar to the soybean oil profile.

Figure 1 also shows the profiles obtained by DIMS for the investigated vegetable oils, verifying the lack of sodium and potassium adducts, as expected; the presence of sodium and potassium adducts would be observed in the vegetable oils analysis by ESI without 18 -crown- 6 dopant. ${ }^{10}$ Therefore, one of the valuable goals of this work was the 


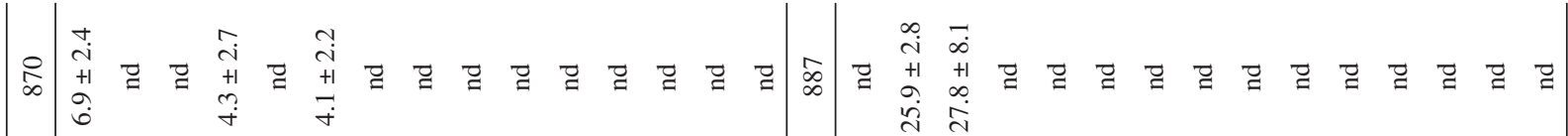

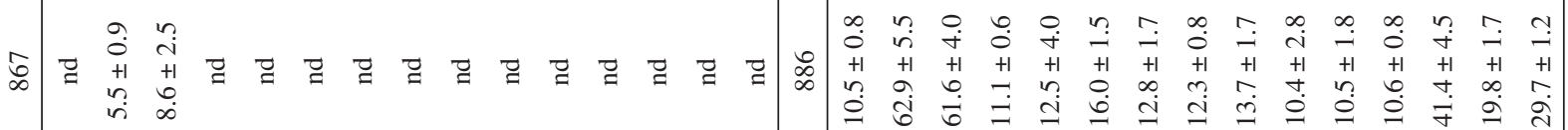

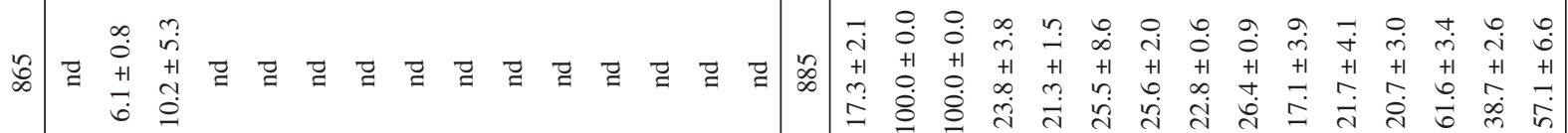

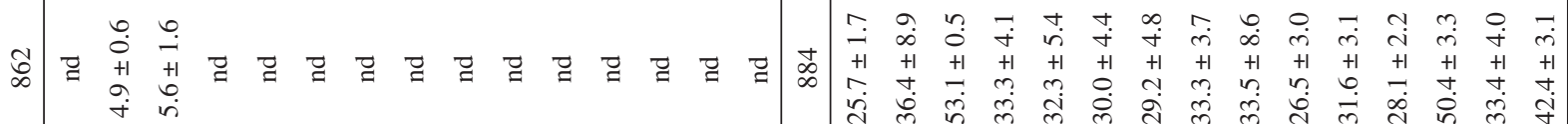

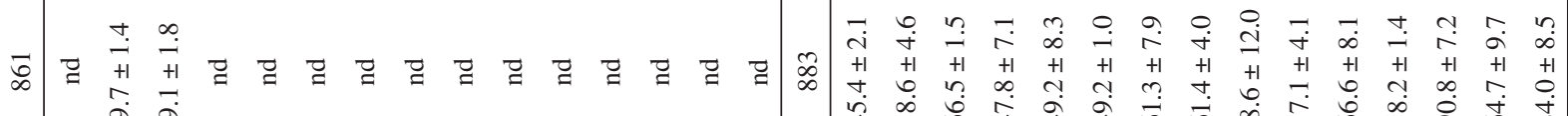

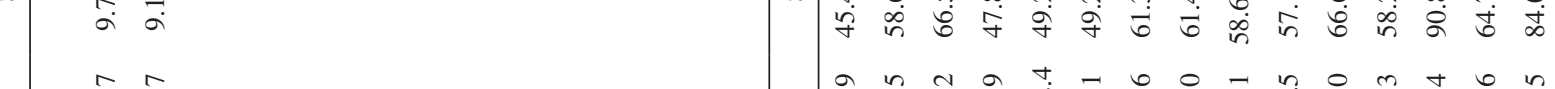

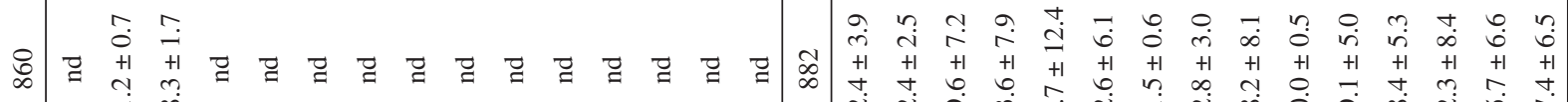
ते

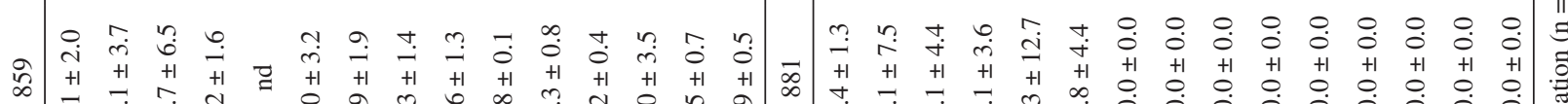

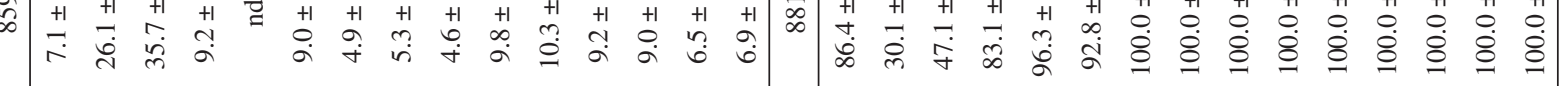

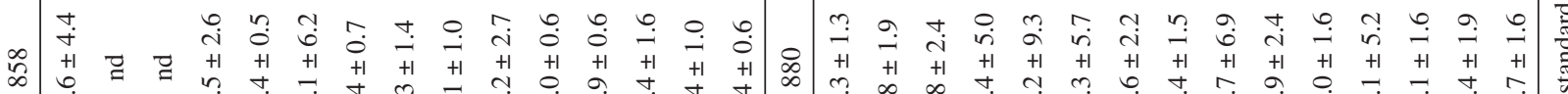

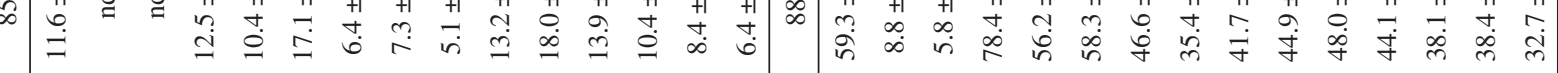

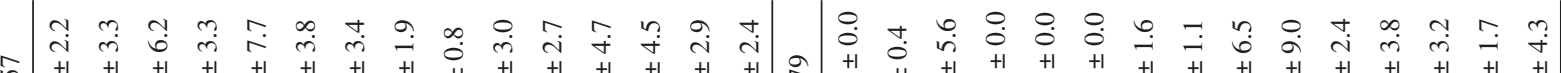

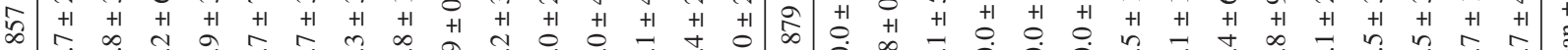
仿

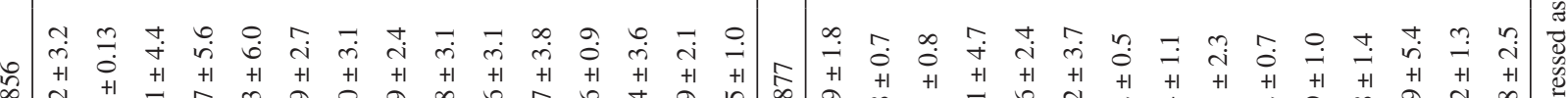

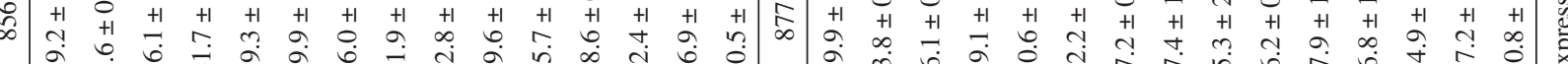
ते $\infty=$ व

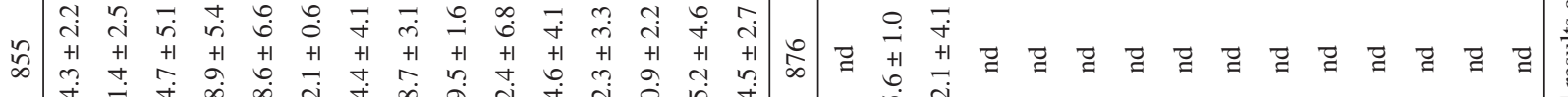

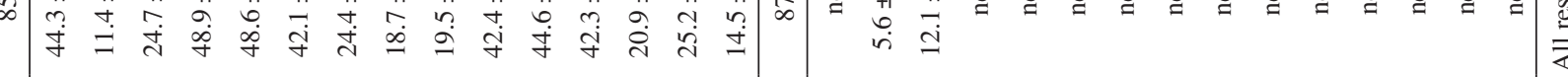

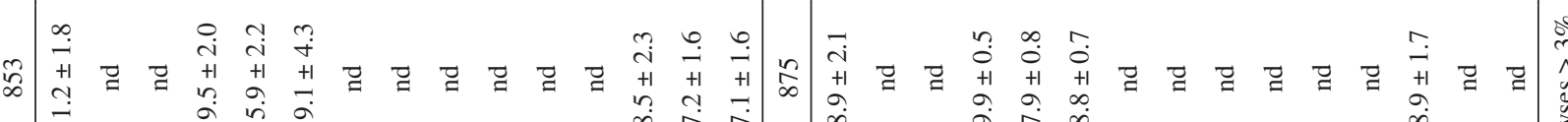

$$
\text { 马 }
$$

胥

+

$\stackrel{T}{+}$

㺃

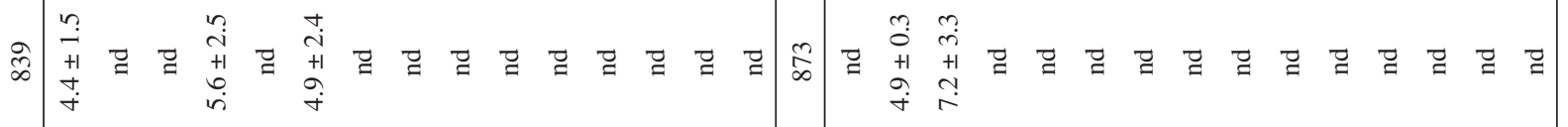

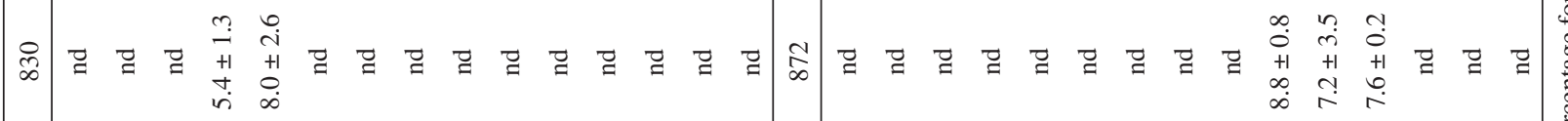

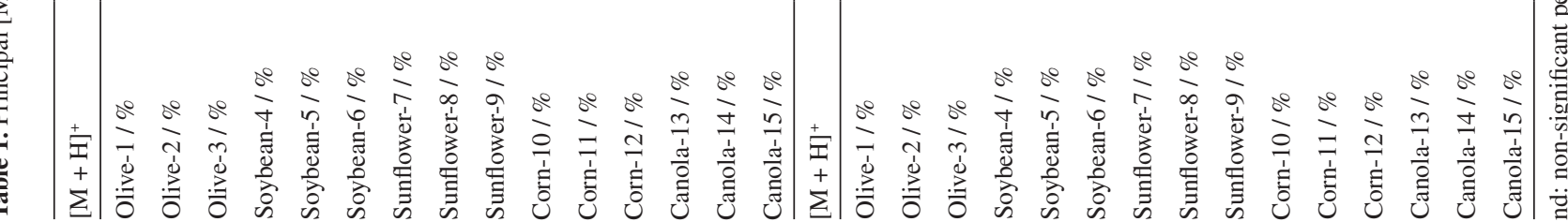


Table 2. Correction factor calculated for the different types of oils using the GC-FID data as the reference for calculation

\begin{tabular}{lccccc}
\hline Oil & $16: 0$ & $18: 0$ & $18: 1 \mathrm{n}-9$ & $18: 2 \mathrm{n}-6$ & 0.3 \\
Olive-3 & 1.4 & 0.3 & 1.4 & 0.7 & $18: 3 \mathrm{n}-3$ \\
Soybean-6 & 2.1 & 1.0 & 1.4 & 0.7 & 1.8 \\
Sunflower-9 & 1.3 & 0.5 & 2.0 & 0.7 & 0.3 \\
Corn-12 & 1.5 & 0.4 & 1.7 & 0.3 & 1.1 \\
Canola-15 & 1.4 & 0.3 & 2.1 & 3.8 \\
\hline
\end{tabular}

16:0: palmitic acid; 18:0: stearic acid; $18: 1 \mathrm{n}$ - 9: oleic acid; $18: 2 \mathrm{n}-6$ : linoleic acid; $18: 3 \mathrm{n}-3$ : linolenic acid.

Table 3. Main fatty acids observed by GC-FID expressed as a percentage of the fatty acid in $1 \mathrm{~g}$ of oil, and main fatty acids observed by DIMS expressed as a percentage of the fatty acid in $10 \mu \mathrm{L}$ of oil using the correction factor calculated in Table 2

\begin{tabular}{|c|c|c|c|c|c|c|c|c|c|c|}
\hline \multirow{2}{*}{ Oil } & \multicolumn{5}{|c|}{ GC-FID } & \multicolumn{5}{|c|}{ ESI-MS } \\
\hline & $16: 0$ & 18:0 & $18: 1 n-9$ & $18: 2 n-6$ & $18: 3 n-3$ & $16: 0$ & 18:0 & $18: 1 n-9$ & $18: 2 n-6$ & $18: 3 n-3$ \\
\hline Olive-1 / \% & $11.5 \pm 3.9$ & $4.4 \pm 3.6$ & $25.3 \pm 3.8$ & $50.6 \pm 3.7$ & $5.5 \pm 3.8$ & $9.2 \pm 0.2$ & $1.2 \pm 0.2$ & $21.4 \pm 0.4$ & $20.8 \pm 0.1$ & $2.8 \pm 0.2$ \\
\hline Olive-1 $1^{\mathrm{a}} / \%$ & - & - & - & - & - & $13.9 \pm 0.2$ & $4.1 \pm 0.2$ & $21.4 \pm 0.4$ & $48.6 \pm 0.1$ & $5.0 \pm 0.2$ \\
\hline Olive- $2 / \%$ & $11.8 \pm 5.5$ & $3.0 \pm 4.8$ & $73.6 \pm 5.1$ & $8.1 \pm 5.9$ & $0.6 \pm 4.9$ & $11.5 \pm 0.6$ & $2.8 \pm 0.4$ & $73.6 \pm 1.6$ & $8.5 \pm 0.8$ & $0.4 \pm 0.1$ \\
\hline Olive- 3 / \% & $12.8 \pm 1.5$ & $2.9 \pm 1.5$ & $69.5 \pm 1.3$ & $9.7 \pm 1.8$ & $0.6 \pm 1.3$ & $12.7 \pm 0.5$ & $2.9 \pm 0.6$ & $65.5 \pm 1.8$ & $10.2 \pm 1.0$ & $0.6 \pm 0.0$ \\
\hline Soybean-4 / \% & $11.4 \pm 4.0$ & $4.7 \pm 5.0$ & $24.8 \pm 2.4$ & $51.3 \pm 2.1$ & $4.9 \pm 2.4$ & $15.0 \pm 0.6$ & $4.0 \pm 0.6$ & $23.4 \pm 1.2$ & $47.0 \pm 1.0$ & $5.9 \pm 0.4$ \\
\hline Soybean-5/\% & $11.5 \pm 5.0$ & $4.5 \pm 5.5$ & $26.8 \pm 3.7$ & $49.5 \pm 4.0$ & $4.7 \pm 7.8$ & $13.7 \pm 0.6$ & $4.2 \pm 0.3$ & $21.4 \pm 0.6$ & $48.9 \pm 0.4$ & $4.7 \pm 0.0$ \\
\hline Soybean-6/\% & $11.4 \pm 2.1$ & $4.4 \pm 1.7$ & $25.2 \pm 2.0$ & $50.9 \pm 2.3$ & $4.9 \pm 2.6$ & $11.1 \pm 1.5$ & $4.2 \pm 0.2$ & $26.0 \pm 3.0$ & $46.9 \pm 1.5$ & $4.9 \pm 0.5$ \\
\hline Sunflower-7 / \% & $5.9 \pm 1.2$ & $3.5 \pm 0.7$ & $38.3 \pm 0.7$ & $49.8 \pm 0.9$ & $0.2 \pm 3.9$ & $6.2 \pm 0.8$ & $3.4 \pm 0.8$ & $43.4 \pm 0.2$ & $46.7 \pm 0.3$ & $0.2 \pm 0.0$ \\
\hline Sunflower-8 / \% & $5.3 \pm 1.2$ & $3.6 \pm 0.6$ & $40.7 \pm 0.7$ & $47.5 \pm 0.9$ & $0.3 \pm 0.2$ & $6.0 \pm 0.3$ & $4.0 \pm 1.6$ & $43.8 \pm 2.4$ & $45.1 \pm 4.1$ & $0.3 \pm 0.3$ \\
\hline Sunflower-9/\% & $5.1 \pm 0.8$ & $3.4 \pm 0.6$ & $40.8 \pm 0.7$ & $48.2 \pm 0.7$ & $0.2 \pm 2.3$ & $5.2 \pm 0.4$ & $3.5 \pm 1.0$ & $40.8 \pm 4.1$ & $47.7 \pm 3.6$ & $0.2 \pm 0.3$ \\
\hline Corn-10 / \% & $12.7 \pm 0.1$ & $2.3 \pm 1.8$ & $33.4 \pm 0.4$ & $48.6 \pm 0.5$ & $0.9 \pm 0.5$ & $11.9 \pm 0.8$ & $2.6 \pm 1.9$ & $33.3 \pm 2.4$ & $46.1 \pm 0.4$ & $0.8 \pm 0.0$ \\
\hline Corn-11 / \% & $12.1 \pm 0.2$ & $2.3 \pm 0.3$ & $35.6 \pm 0.0$ & $47.2 \pm 0.1$ & $0.7 \pm 0.6$ & $11.9 \pm 0.3$ & $2.6 \pm 0.3$ & $34.7 \pm 1.4$ & $44.9 \pm 1.0$ & $0.8 \pm 0.0$ \\
\hline Corn-12 / \% & $12.3 \pm 3.4$ & $2.3 \pm 2.8$ & $36.0 \pm 3.2$ & $46.6 \pm 3.1$ & $0.8 \pm 1.8$ & $12.0 \pm 0.8$ & $2.4 \pm 0.0$ & $36.2 \pm 0.6$ & $44.9 \pm 0.4$ & $0.8 \pm 0.1$ \\
\hline Canola-13 / \% & $4.6 \pm 1.1$ & $2.4 \pm 0.9$ & $60.7 \pm 0.9$ & $19.7 \pm 1.1$ & $7.0 \pm 0.8$ & $5.2 \pm 0.0$ & $2.4 \pm 0.7$ & $57.1 \pm 0.1$ & $17.5 \pm 0.0$ & $7.6 \pm 0.4$ \\
\hline Canola-14 / \% & $7.5 \pm 0.5$ & $3.0 \pm 0.4$ & $48.9 \pm 0.4$ & $32.0 \pm 0.4$ & $3.7 \pm 0.5$ & $6.7 \pm 0.6$ & $1.9 \pm 0.7$ & $50.2 \pm 1.2$ & $18.6 \pm 0.7$ & $6.5 \pm 0.1$ \\
\hline Canola-15 / \% & $4.8 \pm 1.9$ & $2.2 \pm 2.0$ & $60.4 \pm 2.1$ & $19.5 \pm 2.1$ & $7.3 \pm 2.5$ & $4.6 \pm 0.3$ & $2.3 \pm 0.6$ & $58.4 \pm 1.9$ & $17.5 \pm 1.2$ & $7.2 \pm 0.3$ \\
\hline
\end{tabular}

${ }^{a}$ The correction factor defined for soybean oil was also applied, proving the adulteration of the sample. GC-FID: gas chromatography with flame ionization detector; ESI-MS: electrospray ionization mass spectrometry; 16:0: palmitic acid; 18:0: stearic acid; 18:1n - 9: oleic acid; 18:2n - 6: linoleic acid; $18: 3 n-3$ : linolenic acid. All results are expressed as mean \pm relative standard deviation $(n=3)$.

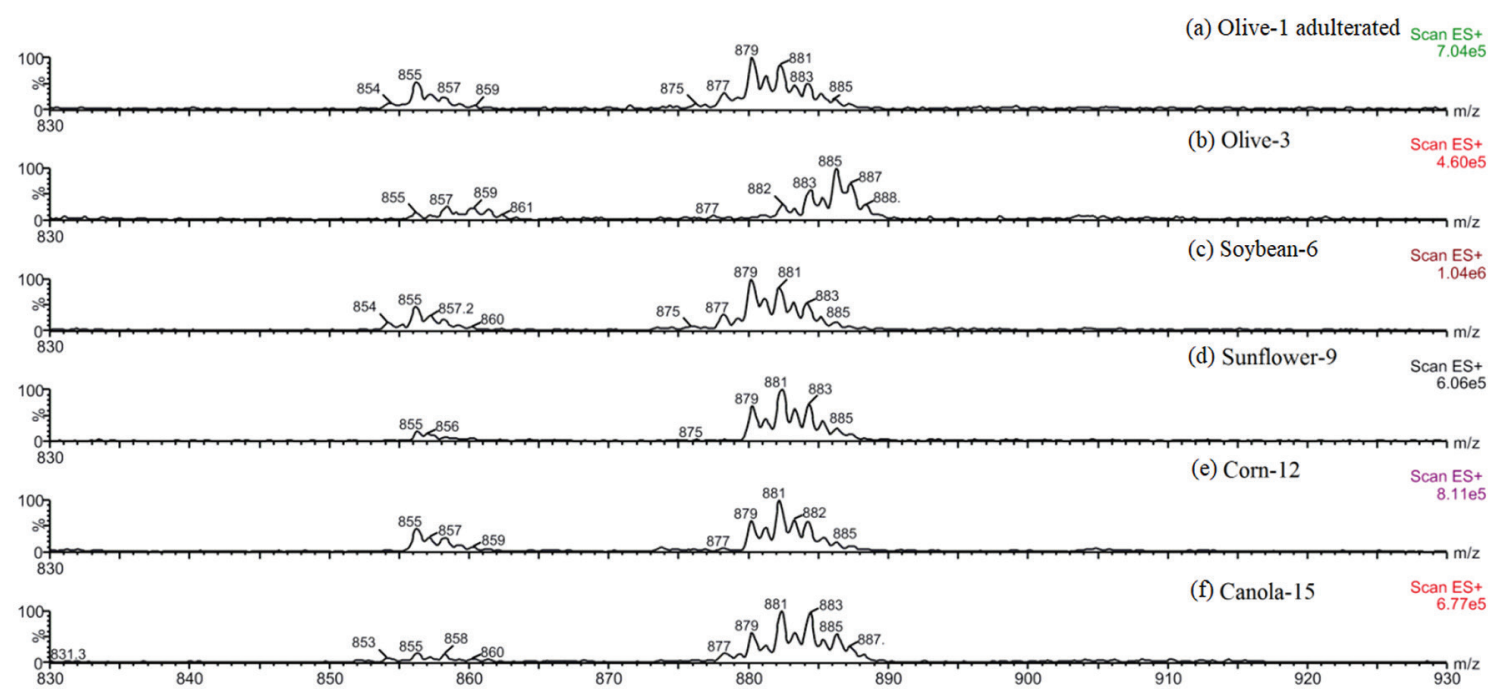

Figure 1. Profile of TAGs obtained for all analyzed oils from the DI-ESI(+)-MS data of the methanolic extracts with ether/TFA: (a) olive-1 adulterated; (b) olive-3; (c) soybean-6; (d) sunflower-9; (e) corn-12; and (f) canola-15. 
use of 18-crown-6 to inhibit the presence of sodiated and potassiated TAGs, favoring protonation by TFA. ${ }^{14}$ Another point is that protonated ions are more easily fragmented than metal cation adducts. It is noteworthy that to date, this is the first complete work to present results of protonated TAGs obtained by rapid DIMS analyses.

The one-ion-one-molecule ${ }^{14}$ feature in the mass spectra facilitates its interpretation since, from visual examination of the spectrum for sample olive-1 (Figure 1a), the ions profile is very similar to that of the soybean oil mass spectrum. In this instance, the full spectrum was not evaluated, but the region $\mathrm{m} / \mathrm{z} 830-930$, considering $\mathrm{m} / \mathrm{z} 879$ the ion of greatest abundance, assigned as the base peak. Ion $\mathrm{m} / \mathrm{z} 879$ was the TAG with three glycerol-esterified linoleic acids (LLL (C54:6)). This TAG profile is characteristic of soybean oil, as observed in the LipidMaps platform ${ }^{24}$ (a free online resource providing data for lipids) and similar articles. ${ }^{3,10,11,25,26}$

It is worthwhile to observe that the TAGs identified were represented by the carbon number sum of the molecule and the number of double bonds, e.g., LLL (C54:4). The most recurrent FAs in the mass spectra were palmitic (P, 16:0), palmitoleic (Po, 16:1), stearic ( $\mathrm{S}, 18: 0)$, oleic $(\mathrm{O}, 18: 1 \mathrm{n}-9)$, linoleic (L, 18:2n-6), and linolenic (Ln, 18:3n-3) acids.

The observed mass spectrum from olive- 3 sample (Figure 1b) led to the TAG identification of PLL (C52:4, $m / z$ 855), POL (C52:3, $m / z$ 857), POO (C52:2, $m / z 859)$, LLL, SLL (C54:4, $\mathrm{m} / \mathrm{z} 883)$, OOO (C54:3, $\mathrm{m} / \mathrm{z} 885)$, and OOS (C52:2, $\mathrm{m} / \mathrm{z} 887)$. The base peak was OOO, the main compound (40-59\%) of olive oil..$^{25}$ Olive-3 sample had the same profile as olive-2. However, olive-1 presented the same profile as the soybean oil samples, with TAG LLL being the most intense. Consequently, it is possible to affirm that the olive- 2 and -3 brands originate from the respective locations described in the corresponding product labels.

Figure 1c displays a representative sample of soybean oil (soybean-6), with the main protonated TAGs as follows: PoLL (C52:5, $\mathrm{m} / z$ 853), PLL, POL, POO, LLLn (C54:7, $\mathrm{m} / z$ 877), LLL, OLL (C54:5, $\mathrm{m} / \mathrm{z}$ 881), SLL, and OOO. Its mass spectrum did not present sodium and potassium adducts, with base peak $[\mathrm{M}+\mathrm{H}]^{+}$for LLL, in all three analyzed brands. According to the literature, around 53\% of the TAG from soybean oil is LLL. ${ }^{25}$ The additional ions are typical of the TAGs that compose this oil, completing the majority (97-99\%) of its total composition, which makes soybean oil one of the richest oils in TAGs among all vegetable oils known. ${ }^{25,26}$

Figure 1d represents a sunflower oil sample (sunflower-9), with suitable agreement among all three analyzed samples. The main TAGs were PLL, POL, LLLn,
LLL, OLL, SLL, and OOO. The base peak ion $[\mathrm{M}+\mathrm{H}]^{+}$ was OLL, characteristic of the TAG from sunflower oil, which is mostly composed of oleic (8-24\%) and linoleic $(67-83 \%)$ acids. $^{25}$

Figure 1e presents a representative corn oil (corn-12) sample, exhibiting great similarity among all evaluated samples. The main TAGs were PLL, POL, LLLn, LLL, OLL, SLL, and OOO, with OLL as the base peak, in accordance with the literature. ${ }^{25}$ The comparison of corn and sunflower oil revealed a slight increase in the abundance of ions coming from PLL and POL TAGs for sunflower.

Figure $1 \mathrm{f}$ represents the TAGs profile obtained by DIMS of canola oil (canola-15), showing the base peak was the ion coming from OLL. Oleic (ca. 64\%) and linoleic (18\%) acids are the most abundant fatty acids constituting canola oil. ${ }^{26}$ It is worth noticing that although the most abundant ion has only one $\mathrm{O}$, the third most abundant peak in canola oil is composed of OOO, which makes it abundant in this variety of fatty acid and differentiates it from the other oils. Additional ions presented were PoLL, PLL, POL, POO, LLLn, LLL, OLL, and SLL.

In general, the spectra obtained for all evaluated vegetable oils revealed a certain similarity. Even though canola, corn, soybean, and sunflower oils could be differentiated by the method, the most distinguishable vegetable oil according to TAG chemical composition was olive oil. Such a finding was expected, given olive oil is considered a high-quality natural product with a superior quality of FAs possessing numerous health benefits, in comparison to other vegetable oils. ${ }^{27}$

\section{Semi-quantitative profile of FAs using TAGs}

The DIMS method resulted in the identification of a variety of ions. The most abundant ions were consistent with results from LipidMaps ${ }^{24}$ and literature (refer to the "Profile of TAGs" sub-section) and TAGs were composed of just five FAs. Table 3 provides both the GC and DIMS data for these FAs only, to compare between the methods; the other FAs observed by GC-FID are not shown here.

To verify if the DIMS technique may be used to estimate the composition percentage of FAs in analyses of TAGs, GC-FID experiments were used as references of composition percentage, by considering the TAGs with the same ionization capacity (a systematic error was introduced, which was corrected by comparing to GC-FID). The aim was to obtain results comparable to literature, presenting the oils composition based on the FAs percentage, namely, the intensity of the TAGs according to individual FA intensity. Thereby, a rapid analysis by MS together with GC-FID calibration is proposed that gives similar results 
to the GC-FID only approach, the most widely employed technique for deciphering oil composition.

One representative sample of each type of oil was chosen. Then, a simple, semi-quantitative calculation was performed through the relative abundance (RA, in \%) of ion, presented in Table 1. The distribution of TAGs abundances was applied to calculate a total percentage (TA; equation 1). TAGs represent more than $95 \%$ of the composition of the oils and so other ions contributing to the total FAs were not considered in the calculation. Subsequently, each TAG exhibited in the spectra was distinguished according to their respective FAs, and the percentage of each FA was calculated by considering its fraction on the TAG. Next, the sum of these individual percentages was termed RA' (equation 2). These two parameters were used to calculate the relative percentages of FAs (equation 3). Equations 1-3 are indicated below and the formulae were applied to linoleic acid $(\% \mathrm{~L})$ :

$$
\begin{aligned}
\text { TA }(\text { TAGs })= & {\left[\frac{\mathrm{RA}}{100}(\mathrm{PoLL})\right]+\left[\frac{\mathrm{RA}}{100}(\mathrm{PLL})\right]+\left[\frac{\mathrm{RA}}{100}(\mathrm{POL})\right]+} \\
& {\left[\frac{\mathrm{RA}}{100}(\mathrm{POO})\right]+\left[\frac{\mathrm{RA}}{100}(\mathrm{LLLn})\right]+\left[\frac{\mathrm{RA}}{100}(\mathrm{LLL})\right]+} \\
& {\left[\frac{\mathrm{RA}}{100}(\mathrm{OLL})\right]+\left[\frac{\mathrm{RA}}{100}(\mathrm{SLL})\right]+\left[\frac{\mathrm{RA}}{100}(\mathrm{OOO})\right] } \\
\mathrm{RA}^{\prime}(\mathrm{L})= & {\left[\frac{\mathrm{RA}}{100} \times \frac{2}{3}(\mathrm{PoLL})\right]+\left[\frac{\mathrm{RA}}{100} \times \frac{2}{3}(\mathrm{PLL})\right]+\left[\frac{\mathrm{RA}}{100} \times \frac{1}{3}(\mathrm{POL})\right]+} \\
& {\left[\frac{\mathrm{RA}}{100} \times \frac{2}{3}(\mathrm{LLLn})\right]+\left[\frac{\mathrm{RA}}{100} \times 1(\mathrm{LLL})\right]+} \\
& {\left[\frac{\mathrm{RA}}{100} \times \frac{2}{3}(\mathrm{OLL})\right]+\left[\frac{\mathrm{RA}}{100} \times \frac{2}{3}(\mathrm{SLL})\right] } \\
\% \mathrm{~L}= & {\left[\frac{\mathrm{RA}}{\mathrm{TA}} \times 100\right] }
\end{aligned}
$$

As the external calibration, a correction factor was considered for each FA observed (Table 2). It was calculated by dividing the value of amount percentage from the GC-FID analysis by the value obtained by DIMS. Next, the resultant correction factors (Table 2) were multiplied by the value obtained in DIMS analyses. However, because an ionization difference between TAGs was not considered, an error occurred, which was minimized using the data correction factor obtained by GC-FID analysis on the semi-quantitative DIMS method. Therefore, the FAs percentage values became close to those presented by GC-FID, expressed in Table 3. The samples olive-3, soybean-6, sunflower-9, corn-12, and canola- 15 have very close values (Table 3), and they are related to those used for the correction factor calculation. Other samples used to test the formula in Table 3 also showed good agreement between the GC-FID and DIMS. The authors are currently testing the method and validating the formula using a larger sample size, aiming to investigate more than 100 soybean oil samples, from a variety of regions in Brazil.

The method reveals the possibility of using GC-FID analysis for calibration and thereafter DIMS analysis to study a large number of samples rapidly. It is noticed that olive-1 sample, treated with the olive oil correction factor, was able to distinguish the adulteration, mainly because it does not match the real value, which is considered to be the result from GC-FID. Nevertheless, when the soybean oil correction factor was applied, it matched the expected value for soybean oil, validating the fraud.

A comparison with the existing data demonstrated it was possible to discern that most of the FAs semi-quantified by DIMS presented values close to those described in the literature. As an example, Zambiazi et al. ${ }^{28}$ determined the free FAs percentage of 20 types of oils, understanding that the percentage values of FAs are extremely close to those obtained by DIMS.

\section{Chemometric analyses}

Exploratory analysis of the data using unsupervised PCA method was performed to verify the possible variables responsible for the greatest data variance. ${ }^{29}$ The values of ionic current that each $\mathrm{m} / \mathrm{z}$ presented were extracted from the mass spectra of each sample, considering only the values that were significant for qualitative analysis (i.e., above $3 \%$ ). Then, these values were normalized to each base peak of its respective sample (Table 1). In this way, the samples were categorized according to their similarities without the requirement of prior information, instead, simply using the instrumental data provided. Analyzing the graphs obtained for the scores and loadings indicated that the use of three principal components did not differentiate samples; although the main component (PC1) was responsible for $87.3 \%$ of the presented variance, $\mathrm{PC} 2$ and $\mathrm{PC} 3$, responsible for $11 \%$, could elucidate the differences between oils better. Thus, because all oils displayed the same TAGs and the difference was just the relative abundance of them in the spectrum, then, unlike PC2 and PC3, PC1 was not suitable to differentiate the samples.

This behavior occurred because the majority of the composition of the oils was the same, with rare masses in greater abundances that could differentiate samples. Through the score analyses (Figure 2) of PC2 (9.35\%) and PC3 $(1.66 \%)$, olive oil was found to be the most distinctive oil in comparison to the others; except olive-1, which was suspected to be adulterated with soybean oil and was represented along with soybean-4, -5 , and -6 . Canola and soybean oils presented similarities to the other oils. Only 
sunflower and corn oils occupied the same quadrant and, on evaluating PC2, can be considered more similar to each other than to the remaining oils studied. However, on assessing PC3, a certain similarity between corn, sunflower, and canola oils is evident. The loadings were not presented in this article. Nonetheless, they corroborate with the profile of TAGs data (refer to the "Profile of TAGs" sub-section, above), given that the major ions that differentiated olive oil were OOO (C54:3, $\mathrm{m} / \mathrm{z}$ 885); soybean oil, LLL (C54:6, $\mathrm{m} / \mathrm{z}$ 879); corn oil, OLL (C54:5, $\mathrm{m} / \mathrm{z}$ 881); sunflower oil,
OLL (C54:5, $\mathrm{m} / \mathrm{z}$ 881), PLL (C52:4, $\mathrm{m} / \mathrm{z} 855)$, and POL (C52:3, $\mathrm{m} / \mathrm{z} 857$ ), and for canola oil, OLL (C54:5, $\mathrm{m} / \mathrm{z} 881$ ) and $\mathrm{OOO}(\mathrm{C} 54: 3, \mathrm{~m} / \mathrm{z}$ 885).

The heatmap generated (Figure 3 ) further accentuated the similarity between soybean and adulterated olive oil; both samples presented the same masses in greater abundance in both spectra and the heatmap. Olive-1 and olive- 2 were distinct from the other oils in relation to the specific masses presented in the heatmap, which matched the PCA. The other oils indicated similarities and

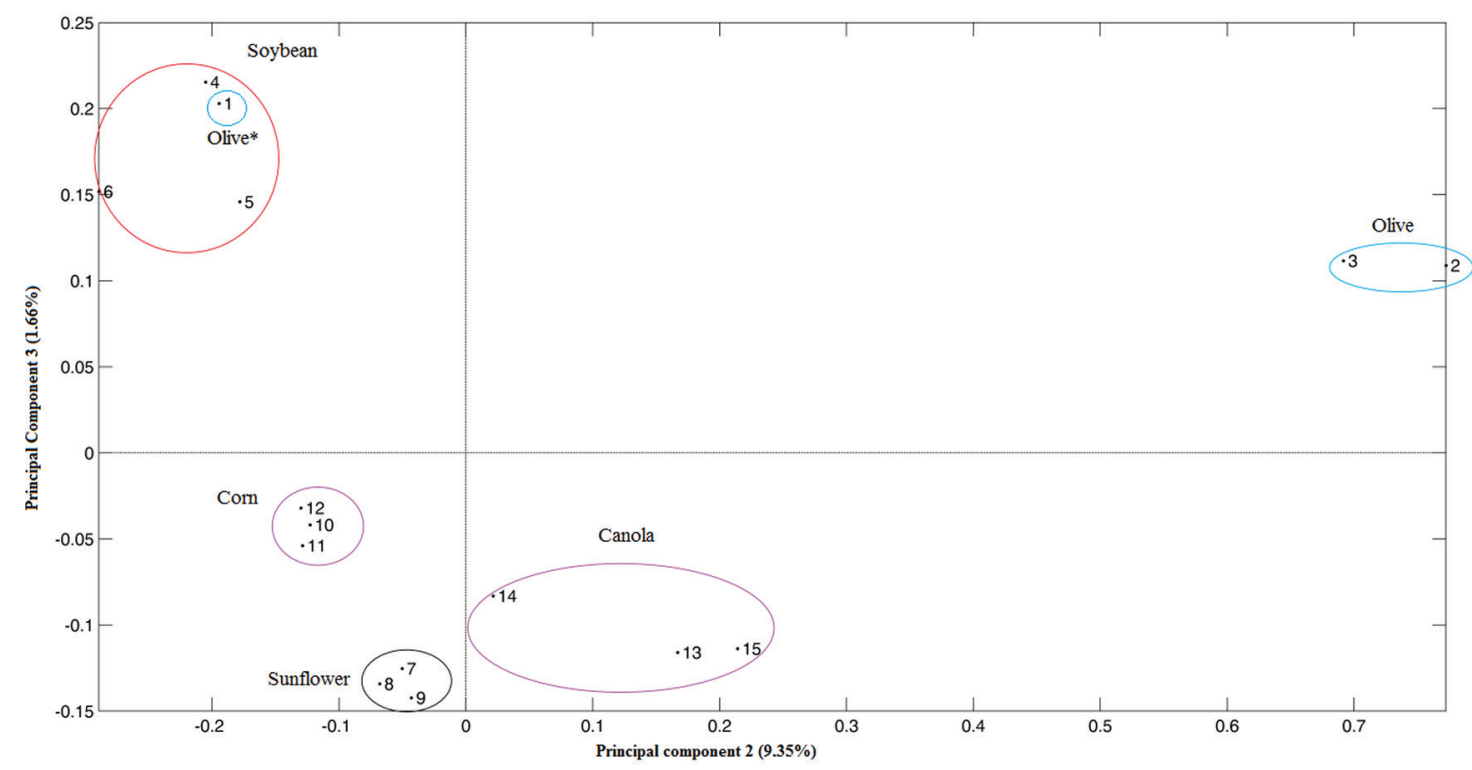

Figure 2. Scores plot for PC2 and PC3 obtained from the DI-ESI(+)-MS data of the methanolic extracts with ether/TFA of oils: olive (1-3), soybean (4-6), sunflower (7-9), corn (10-12), and canola (13-15). Note that olive-1 appears along with the group of soybean oil, proving its adulteration with this type of oil.

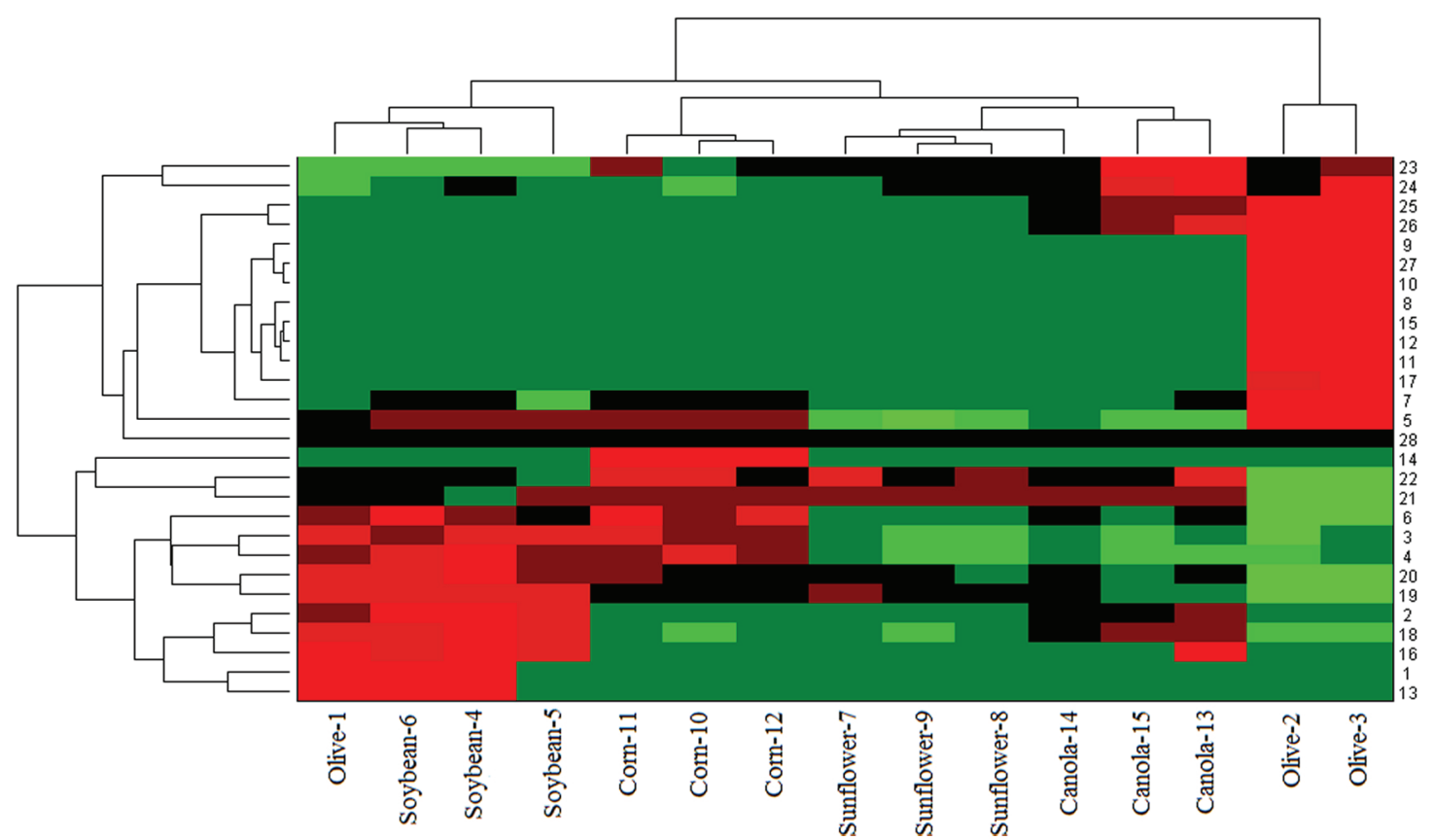

Figure 3. Heatmap referring to the main $\mathrm{m} / \mathrm{z}$ obtained from the DI-ESI(+)-MS data for all the oils. 
differences between them, but these were less significant than olive and soybean oils.

\section{Conclusions}

The use of 18-crown-6 ether made this work unprecedented, allowing the analysis of TAGs free of sodium and potassium adducts, as well as eliminating associated isobaric interferences. Besides, the percentage value of each FA was determined by semi-quantitative analysis. Also, it was possible to elaborate a correction factor for these results. This strategy practically allows semi-quantitative analysis of FAs by DIMS, without long periods of sample preparation, as required in GC-FID determination.

Through the chemometric analysis by PCA and heatmap, it was possible to confirm the similarities and differences between the oils, which was already verified with MS; one sample of olive oil was dramatically dissimilar from the other two olive oil samples in PCA and heatmap, and it had a similar profile to soybean oil.

\section{Acknowledgments}

We thank Waters Technologies for the Premier XE equipment that was installed in Fenn Lab, and all the support in conducting the experiments at UFPR Jandaia do Sul. We also thank UFPR and UEM for the financial support.

\section{References}

1. Sant'Ana, L. S.; Braz. J. Med. Biol. Res. 2004, 17, 211.

2. de Souza, N. E.; Visentainer, J. V.; Colesterol - da Mesa ao Corpo, $2^{\mathrm{a}}$ ed.; Eduem: Maringá, 2012.

3. Wu, Z.; Rodgers, R. P.; Marshall, A. G.; J. Agric. Food Chem. 2004, 52, 5322 .

4. Karmal-Eldin, A.; Eur. J. Lipid Sci. Technol. 2006, 108, 1051.

5. Babicz, I.; Leite, S. G. F.; de Souza, R. O. M. A.; Antunes, O. A. C.; Ultrason. Sonochem. 2010, 17, 4.

6. Gamazo-Vázquez, J.; Garcia-Falón, M. S.; Simal-Gándara, J.; Food Control 2003, 14, 463.

7. Wolf, C.; Quinn, P. J.; Prog. Lipid Res. 2008, 47, 15.

8. Seiwert, B.; Giavalisco, P.; Willmitzer, L. In Lipids in Photosynthesis. Advances in Photosynthesis and Respiration, vol. 30; Wada, H.; Murata, N., eds.; Springer: Dordrecht, 2009 , p. 445 .
9. Catharino, R. R.; Haddad, R.; Cabrini, L. G.; Cunha, I. B. S.; Sawaya, A. C. H. F.; Eberlin, M. N.; Anal. Chem. 2005, 77, 7429.

10. Simas, R. C.; Catharino, R. R.; Cunha, I. B. S.; Cabral, E. C.; Barrera-Arellano, D.; Eberlin, M. N.; Albereci, R. M.; Analyst 2010, 135, 738.

11. Li, M.; Butka, E.; Wang, X.; Sci. Rep. 2014, 4, 6581.

12. Alves, J. O.; Neto, W. B.; Mitsutake, H.; Alves, P. S. P.; Augusti, R.; Rapid Commun. Mass Spectrom. 2010, 24, 1875.

13. Cech, N. B.; Enke, C. G.; Mass Spectrom. Rev. 2001, $20,362$.

14. Tonin, A. P. P.; Ribeiro, M.; Silva, V. M.; Oliveira, C. C.; Saragiotto, M. H.; Eberlin, M. N.; Meurer, E. C.; Int. J. Mass Spectrom. 2017, 418, 37.

15. Siciliano, C.; Belsito, E.; Marco, R.; Gioia, M. G.; Leggio, A.; Liguori, A.; Food Chem. 2013, 136, 546.

16. Leggio, A.; Belsito, E. L.; De Marco, R.; Liguori, A.; Siciliano, C.; Spinella, M.; J. Chromatogr. A 2012, 1241, 96.

17. Aursand, M.; Standal, I. B.; Axelson, D. E.; J. Agric. Food Chem. 2007, 55, 38.

18. Tyl, C. E.; Brecker, L.; Wagner, K.-H.; Eur. J. Lipid Sci. Technol. 2008, 110, 141.

19. Hartman, L.; Lago, R. C. A.; Lab. Pract. 1973, 22, 475.

20. Maia, E. L.; Rodriguez-Amaya, D. B.; Rev. Inst. Adolfo Lutz 1993, 53, 27.

21. Soares, I. P.; Russo, R. M. O.; Prates, R. G. D.; Augusti, R.; Fortes, I. C. P.; Pasa, V. M. D.; Quim. Nova 2011, 34, 1439.

22. Software Matlab, v 7.0; MathWorks Inc, Natick, MA, USA, 2006.

23. Metsalu, T.; Vilo, J.; Nucleic Acids Res. 2015, 43, 566.

24. http://www.lipidmaps.org, accessed in September 2018.

25. Gunstone, F. D.; Vegetable Oils in Food Technology: Composition, Properties and Uses, $3^{\text {rd }}$ ed.; Blackwell Publishing: Oxford, 2011.

26. Damodaran, S.; Parkin, K. L.; Fennema, O. R.; Química de Alimentos, $4^{\mathrm{a}}$ ed.; Artmed: Porto Alegre, 2010.

27. Mello, L. D.; Pinheiro, M. F.; Braz. J. Food Nutr. 2012, 23, 537.

28. Zambiazi, R. C.; Przybylski, R.; Zambiazi, M. W.; Mendonça, C. B.; Bol. Cent. Pesqui. Process. Aliment. 2007, 25, 111.

29. Tautenhahn, R.; Patti, G. J.; Rinehart, D.; Siuzdak, G.; Anal. Chem. 2012, 84, 5035.

Submitted: July 3, 2018 Published online: September 20, 2018 